\title{
Physico-chemical characterization of olive-oil mill wastewaters of Ben Karrich area (Tetouan province, North of Morocco) and optimization study of their treatment using activated carbon
}

\author{
Dorsaf Bouharat*, Nabila Slimani Alaoui, Badr Dine Souhail, Anas El Laghdach, Farida El Yousfi \\ Laboratory of Water, Studies and Environmental Analysis, Department of chemistry, Faculty of Sciences, \\ University Abdelmalek Essaâdi, B.P. 2121, Mhannech II, 93002 Tetouan, Morocco.
}

\begin{abstract}
A physio-chemical characterization of olive oil mill wastewater (OMW) obtained from a continuous two-phases olive oil extraction process is presented. High organic load of OMW from Ben Karrich region has been registered. The values of chemical oxygen demand (COD) and total phenolic compounds were $84.5 \mathrm{~g}$ of $\mathrm{O}_{2} / \mathrm{L}$ and $3.79 \mathrm{~g} / \mathrm{L}$, respectively. In this sense, a treatment using activated carbon as adsorbent was proposed. Results have shown high removal percentages in total phenolic compounds (98\%) and COD (90\%). The optimal operating conditions were $4 \mathrm{~g}$ of activated carbon and adsorbing time equal to 5 minutes.
\end{abstract}

Keywords: OMW; characterization; adsorption; activated carbon; optimization.

\section{Introduction}

The olive tree constitutes the main fruit species planted in Morocco; it extends over a surface of 784.000 hectares, the national exploitations reach a production around 1.500.000 tons of olives. Morocco also produces 160.000 tons of olive oil ${ }^{1}, 18 \%$ of this production is assured by the North region according to the Regional Agriculture Office of the region Tanger-Tétouan-Al Hoceima. Since the inauguration of the Green Plan in Morocco (GPM) in 2009. The region has experienced a significant increase regarding areas planted with an olive tree; it was extended from 98600 ha in 2009 to approximately 200000 ha in 2017 , furthermore the creation of 16 units of trituration of a daily production capacity oscillating between 20 and 60 tons ${ }^{2}$.

The production and the transformation of olives are generally assured by oil manufacture, which transforms olives into oil. This extraction engenders the production of two types of residues, the olivepomace and the OMW. The latter comes from the water added during the process of the extraction and that used in the wash and the vegetation of olives, and they cause a severe problem during their evacuation in the natural environment such as rivers. Receiving waters indeed become strongly charged in organic matter and pollutants and lose their capacity to auto-purify ${ }^{3}$.
The toxicity of OMW is essentially due to a long chain of free fatty acids and a high concentration of phenolic compounds ( 4 to $15 \mathrm{~g} / \mathrm{L}$ ).

The non-biodegradability of OMW is due to the phytotoxicity and antimicrobial effects of these products, hence the interest in a treatment that reduces their polluting ${ }^{4}$.

Various treatment processes of OMW were developed: physical, chemical and biological processes and a combined system. The current trends should pursue the integration of diverse, low-cost technologies for OMW treatment. This requires the production of an added value susceptible to cover the costs of the treatment. Consequently, the treatment of these OMW by adsorption seems to be the best technique due to its simplicity ${ }^{5}$.

This work aims to characterize the OMW stemming from a modern olive oil extraction system, which operated using a Decanter with two-exits situated in Ben Karrich's region. Besides studying the treatment of OMW by adsorption on activated carbon to eliminate the phenolic compounds. The operating conditions also were studied and optimized. 


\section{Experimental}

\section{OMW origin}

The used OMW were recovered from a modern olive oil extraction unit with a continuous two phased system located in the region of Ben Karrich (Tetouan Province -North of Morocco)

Sampling was made in a different period of the agricultural season for 2 years: 2016-2017. The samples were collected in opaque glass bottles.

\section{Adsorbent:}

The adsorbing support used in this work is commercial activated carbon powder.

\section{Methods}

Physico-chemical analysis of OMW

Except for total suspended solid (TSs) and total solid (TS) determination, before the determination of all physicochemical parameters, OMW samples were filtered under atmospheric pressure and settled using a separating funnel.

So the characterization of OMW was carried out as follow, and all parameters were analyzed three times:

To measure the $\mathrm{pH}$, a multi-parameter analyze consort (L562) pH meter was used.

The total solid (TS) was measured by the standard methods of RODIER ${ }^{6}$.

The total suspended solid (TSs) was a determined using a filter with $0.45 \mu \mathrm{m}$ pore diameter. After filtration, filter was dried in an oven at $105^{\circ} \mathrm{C}$ for $4 \mathrm{~h}^{7}$, then TSs content was calculated by the filter's weight difference before and after filtration.

The chemical oxygen demand (COD) was determined using a photometric method based on the oxidation at $150^{\circ} \mathrm{C}$ of organic matter by an excess of potassium dichromate in an acid media in the presence of silver sulfate ${ }^{8}$. COD concentration was measured using photometer (AQUALYTIC COD VARIO).

The biological oxygen demand (BOD5) was determined by the respirometry method. An appropriate amount of sample was introduced in BOD bottles and settled in a thermostatic chamber at $20^{\circ} \mathrm{C}$ in the dark. The oxygen value was measured over 5 days.

Fats were extracted from OMW by chloroform and methanol; After an agitation followed by settling, the mixture was divided into two phases. The superior phase constituted by OMW and methanol was eliminated, while the lower phase containing the soluble chloroform and fats was evaporated in a rotary evaporator (Nahita, Rotary Evaporator 9200. Fats were calculated by weight difference $^{9}$.
The phenolic compounds were quantified by the colorimetric method using the gallic acid as a standard. The absorbance was measured at $750 \mathrm{~nm}$ using uv-visible spectrophotometer varian cary $50{ }^{10}$.

Total sugars were determined by colorimetric method, using the glucose as a standard at $488 \mathrm{~nm}$. Orthophosphates were dosed using a colorimetric method based on the formation of antimonyphospahte-molybdate complex. The reduction of this complex using ascorbic acid leads to a strongly bluecolored compound ${ }^{11}$.

Calcium $\left(\mathrm{Ca}^{2+}\right)$ and magnesium $\left(\mathrm{Mg}^{2+}\right)$ ions were dosed by the volumetric titration method of EDTA ${ }^{12}$. Chlorides $\left(\mathrm{Cl}^{-}\right)$were dosed by the Mohr method ${ }^{13}$.

\section{Adsorption experiences}

Since the adsorbing support used for the adsorption of the phenolic compounds of OMW is a commercial activated carbon, we realized a study of optimization of factors influencing the adsorption, to have a better efficiency while minimizing the costs. The parameters, which were studied, are contact time, $\mathrm{pH}$, adsorbent concentration, temperature and agitation speed.

The adsorption of OMW using activated carbon was realized in standard conditions at ambient temperature and pressure in an orbital agitator (IKA KS 4000 I control).

In a series of $250 \mathrm{ml}$ glass bottles, $100 \mathrm{ml}$ of OMW diluted to $10 \%$ with distilled water was added a certain mass of activated carbon, this solution is agitated permanently. At the end of this experience, this solution is filtered, and the phenolic compounds content of the substrate was determined by the colorimetric method ${ }^{10}$.

The equilibrium adsorption amount of phenol qe $(\mathrm{mg} / \mathrm{g})$ and the elimination percentage was calculated by the following expressions :

$q e=\frac{(\mathrm{Co}-\mathrm{Ce}) * \mathrm{~V}}{\mathrm{~m}}$

Elimination percentage $(\%)=\frac{(\mathrm{C} 0-\mathrm{Ce}) * 100}{\mathrm{C} 0}$

Were $\mathrm{C}_{0}$ and $\mathrm{Ce}$ are respectively the initial mass concentration and the mass concentration at equilibrium of the phenolic compounds ( $\mathrm{mg} / \mathrm{L}$ ), $\mathrm{V}$ is the solution volume (L) and $\mathrm{m}$ is the mass of the activated carbon used $(\mathrm{g})$.

\section{Results and Discussion}

\section{Characterization of OMW}

Table 1 represents the average values obtained from different physicochemical parameters of studied OMW. 
Table1. physicochemical parameters of OMW from a modern olive oil extraction unit.

\begin{tabular}{|c|c|}
\hline Parameter & Value \\
\hline pH & 4,58 \\
\hline Total suspended solid (TSs) (g/L) & 8,45 \\
\hline Total solid( TS) $(\mathrm{g} / \mathrm{L})$ & 51 \\
\hline $\mathrm{COD}\left(\mathrm{g}\right.$ of $\left.\mathrm{O}_{2} / \mathrm{l}\right)$ & 84,5 \\
\hline $\mathrm{BOD}_{5}\left(\mathrm{~g}\right.$ of $\left.\mathrm{O}_{2} / \mathrm{l}\right)$ & 15,75 \\
\hline Fats $(g / L)$ & 0,46 \\
\hline Phenolic compounds (g/L) & 3,43 \\
\hline Total sugars $(\mathrm{mg} / \mathrm{L})$ & 45,53 \\
\hline Orthophosphates (mg/L) & 130 \\
\hline Calcium (mg/L) & 166 \\
\hline Magnesium (mg/L) & 410 \\
\hline Chlorides (mg/L) & 1840 \\
\hline
\end{tabular}

The Table above indicates that the studied sample is acid effluents because of their $\mathrm{pH}$ value that was obtained in the order of 4,58. This value is similar to the one obtained by Mandi et al. ${ }^{14}$. The content in Total suspended solid is relatively low comparing it with the one obtained by Aissam et al. which is to $18 \mathrm{~g} / \mathrm{L}^{9}$, This is due to the low water use during the olive oil extraction by the two phased centrifugation system ${ }^{15}$ The rate of the total solid is similar to that obtained by Mandy et al. $(56,75 \mathrm{~g} / \mathrm{L})$ 14 . The content of OMW with pollutants is expressed in terms of the chemical oxygen demand (COD) and The biological oxygen demand (BOD5) which are respectively in the order of $84,5 \mathrm{~g} / \mathrm{L}$ and $15,75 \mathrm{~g} / \mathrm{L}$. Finally, the content in phenolic compounds is in the order of $3,43 \mathrm{~g} / \mathrm{L}$. This concentration could limit any natural biodegradation and consequently could lead to a more or less deep disturbance of the whole receiving ecosystem.
This high concentration of phenolic compounds could limit any natural biodegradation, and consequently, it causes a more or less deep perturbation of the entire receiving ecosystem. Therefore, why is it necessary to treat these effluents to eliminate the polyphenols that they contain and to facilitate their valorization.

\section{Adsorption experiments \\ Optimization of factors influencing the adsorption \\ Contact Time}

To study the contact time effect we fixed the following operating conditions: mass of carbon $=2$ $\mathrm{g}, \mathrm{pH}=5(\mathrm{pH}$ of OMW after dilution), agitation speed=200 rpm, Volume $=100 \mathrm{ml}$ and Ambient temperature.

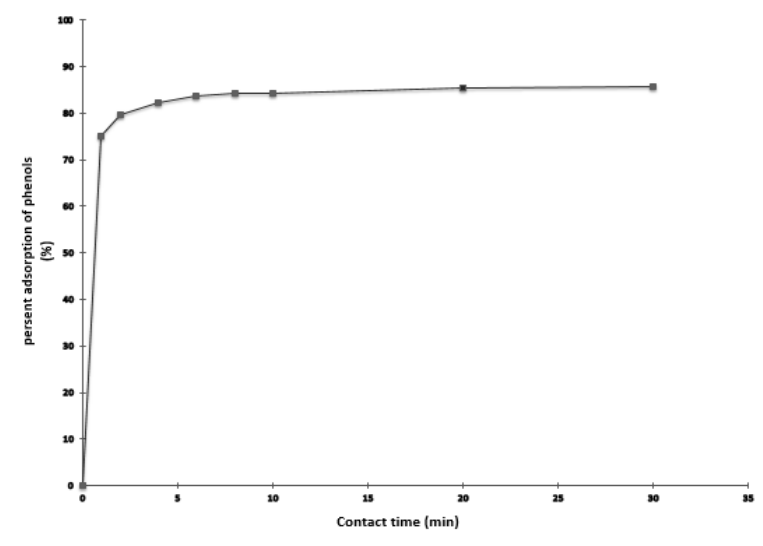

Figure 1. Contact time effect on the phenolic compounds adsorption of OMW using activated carbon.

The results showed that we reached adsorption equilibrium after $5 \mathrm{~min}$, This duration corresponds to the time required for attachment of phenolic compounds molecules that uses activated carbon, and that achieves saturation. This result is similar to those obtained by QADEER et al. ${ }^{16}$; the latter has revealed that the phenols adsorption process on activated carbon reaches equilibrium after $5 \mathrm{~min}$.

By comparing this equilibration time with that of N. Slimani $(20 \mathrm{~min}){ }^{17}$ who studied the adsorption of the phenolic compounds on activated carbon made by bones, we find that our adsorption rate is very fast. 


\section{pH effect}

The $\mathrm{pH}$ is an essential parameter to be taken into account during the adsorption processes. This parameter acts on the solubility as well as on the state of the adsorbent ionization. Athe wide $\mathrm{pH}$ range from 1 to 10 was studied while setting the following parameters: Volume of OMW $100 \mathrm{ml}$, mass of carbon $=4 \mathrm{~g}$, agitation speed $=200 \mathrm{rpm}$ at ambient temperature. Acidic and basic $\mathrm{pH}$ is obtained firstly by addition of a hydrochloric acid solution $(0,1 \mathrm{~N})$ and secondly by addition of caustic soda solution $(0,1 \mathrm{~N})$.

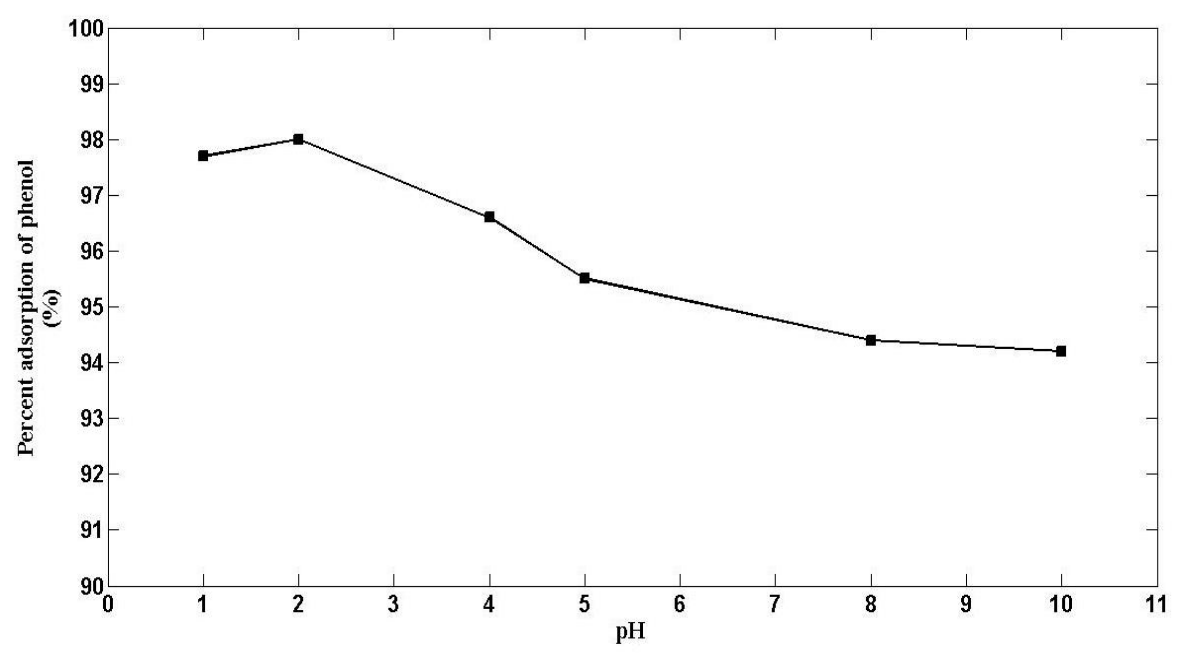

Figure 2. $\mathrm{pH}$ effect on the phenolic compounds adsorption of OMW using the activated carbon.

According to the above results, we see that the polyphenols elimination percentage is important for all acidic pHs. This percentage reaches a maximum that exceeds $98 \%$ at $\mathrm{pH}=2$. As a result, the passage from an acidic $\mathrm{pH}$ to a basic $\mathrm{pH}$ disadvantage the polyphenols retention, this is related to the conversion of the functional group charge of activated carbon as well as of the polyphenols molecules. When based on the $\mathrm{pH}$ and $\mathrm{pKa}$ value, when the $\mathrm{pH}$ of the solution is greater than $\mathrm{pKa}$ of the phenolic compounds $(\mathrm{pH}>\mathrm{pKa})$. The latter is in the form of phenolate ions (C6H5O-) they are negatively charged, and the functional groups at the surface of carbon are deprotonated and negatively charged. Resulting in repulsion and decreasing the adsorption capacity, whereas when the $(\mathrm{pH}<\mathrm{pKa})$ the phenolic compounds are in their neutral form. The interactions that occur between the aromatic compounds electrons and the carbon's surface by their adsorption ${ }^{18,19}$.

\section{Adsorbent rate effect}

The operating conditions fixed to study the influence of adsorbent rate on the phenolic compounds adsorption are Volume of OMW $100 \mathrm{ml}$, the mass of carbon from $0,5 \mathrm{~g}$ to $5 \mathrm{~g}, \mathrm{pH} 2$, agitation speed $=200 \mathrm{rpm}$, contact time $30 \mathrm{~min}$ at ambient temperature.

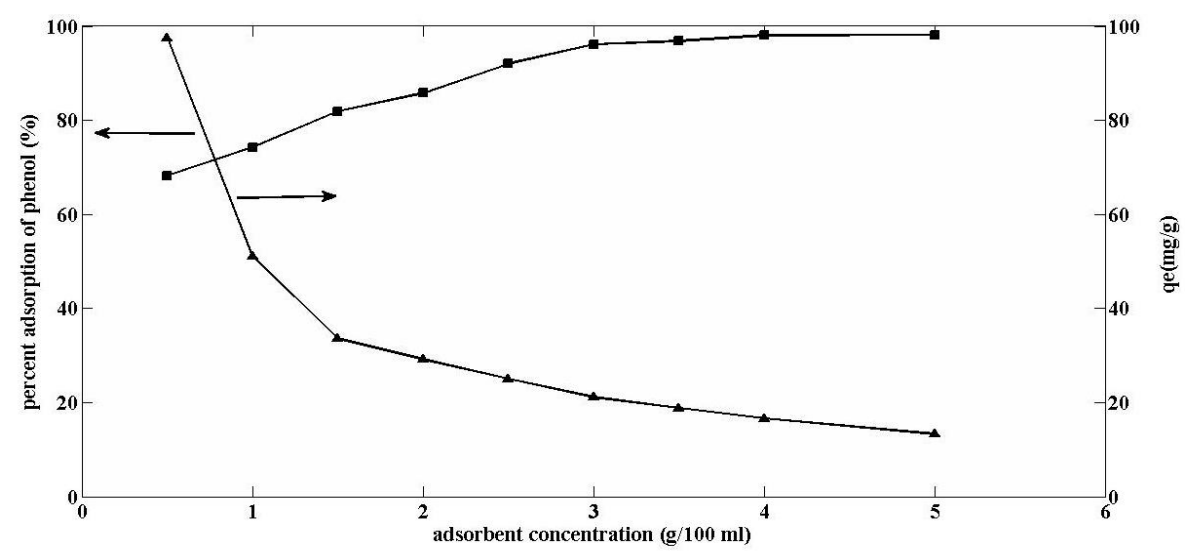

Figure 3. Adsorbent concentration influence on the phenolic compounds adsorption using activated carbon

The Figure above shows that when we increase the activated carbon concentration from 10 to $50 \mathrm{~g} / \mathrm{L}$, the elimination percentage of the phenolic compounds increase from $65 \%$ to $98 \%$ for $\mathrm{S} / \mathrm{L} 4 \mathrm{~g} / 100 \mathrm{ml}$, at the 
end of this concentration the adsorption is almost constant. These results may be explained in the following manner: for more adsorbing material quantity, more adsorption sites are available, so more polyphenols molecules can be attached to these sites. However, up to $40 \mathrm{~g} / \mathrm{l}$ of activated carbon concentration, the active sites number becomes constant ${ }^{20}$.

\section{Agitation speed effect}

In order to study the influence of the agitation speed on the phenolic compounds adsorption, we fixed the following operating conditions: volume of OMW $100 \mathrm{ml}$, the mass of activated carbon $4 \mathrm{~g}$, and $\mathrm{pH} 2$, contact time $30 \mathrm{~min}$ at ambient temperature.

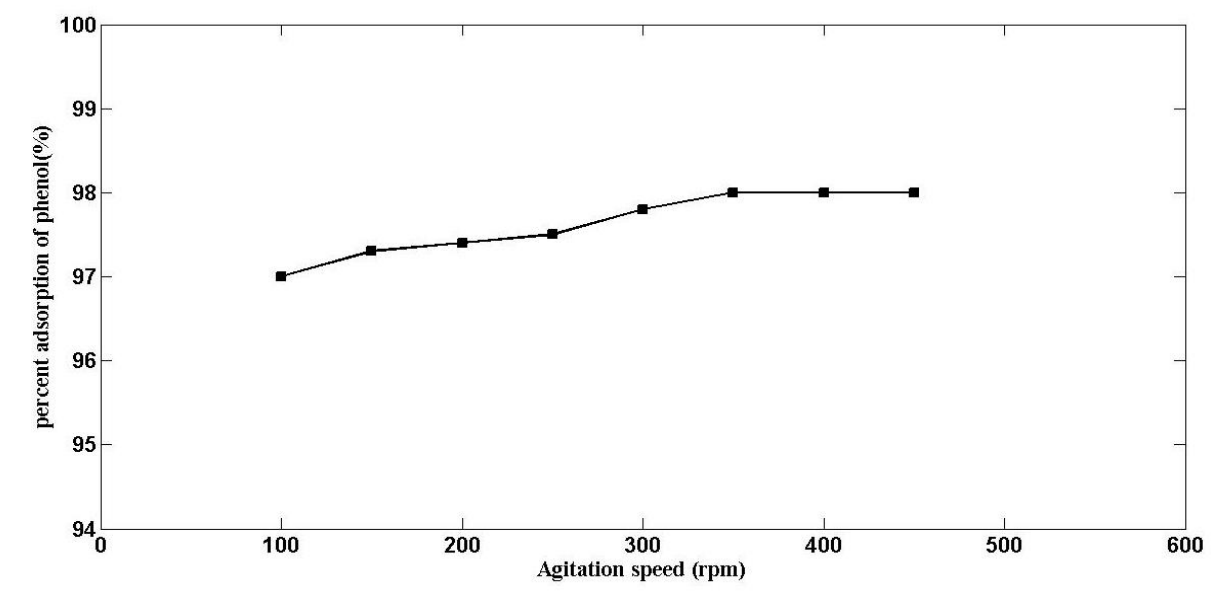

Figure 4. Agitation speed influence on the phenolic compounds adsorption using activated carbon.

The Figure above shows that the elimination rate of the phenolic compounds increases slightly with the agitation speed until we obtain a bearing. The maximal of the elimination percentage was obtained at a speed of $350 \mathrm{rpm}$.

\section{Temperature effect}

To determine the optimal temperature, which allows the best adsorption; studies have been carried out using a thermostatic orbital agitator to maintain the desired temperature (between $10^{\circ} \mathrm{C}$ and $50^{\circ} \mathrm{C}$ ). The experiments were conducted by adding $4 \mathrm{~g}$ of activated carbon to $100 \mathrm{ml}$ of diluted OMW in $10 \%$ at $\mathrm{pH} 2$ and an agitation speed of $350 \mathrm{rpm}$.

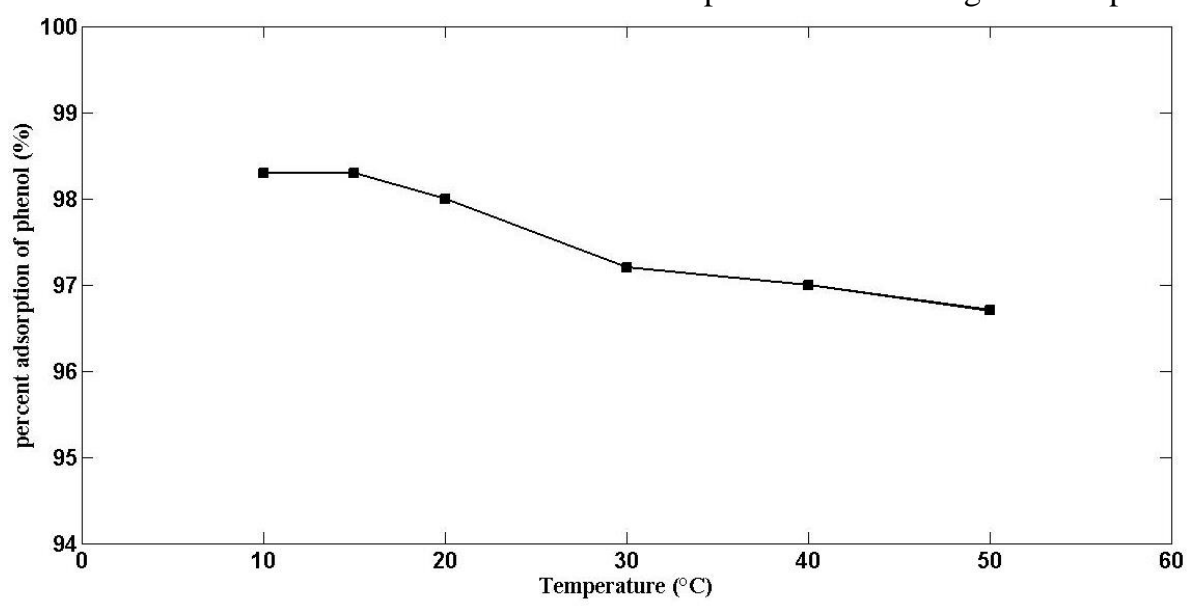

Figure 5. Temperature influence on the phenolic compounds adsorption using activated carbon.

The Figure above shows a decrease of the polyphenols retention with the increase of temperature; this can be explained by the exothermic process of the adsorption and by the weak association between polyphenols and the active sites of the activated carbon ${ }^{21}$ for higher temperatures. So, the best results concerning adsorption are obtained between 10 and $20^{\circ} \mathrm{C}$.

\section{Conclusion}

Physicochemical characterization of OMW obtained from two-phased modern olive oil extraction unit located in ben Karrich's region (Provence of Tétouan-North of Morocco) show that this kind of wastewater have an acidic $\mathrm{pH}$, high content of total suspended solid, total solid, fats and Polyphenols. 
The OMW treatment using activated carbon was able to eliminate more than $98 \%$ of the polyphenols, the best elimination rate was obtained at $15^{\circ} \mathrm{C}$ using $4 \mathrm{~g}$ of activated carbon, during $5 \mathrm{~min}$ at $\mathrm{pH}=2$ with speed agitation equal to $350 \mathrm{rpm}$.

\section{References}

1- Ministère de l'agriculture de la pêche maritime du développement rural et des eaux et forêts, filière oléicole.

http://www.agriculture.gov.ma/pages/accesfillieres/filiere-oleicole

2- http://www.agrimaroc.ma/production-olivesrecord-tanger/

3- Anonyme, 2003, l'Industrie Oléicole au Maroc et son impact sur l'Environnement Propositions d'actions de lutte contre la pollution générée par les Huileries d'Olives Cas de la Province de Taounate, document du sécrétariat d'état chargé de l'environnement.

4- $\quad$ A. Zahari, 1, A.1 Tazi, M.1 Azzi, Optimization of treatment conditions of Olive Oil Mill Wastewater by superoxidant K3FexMnyO8 , J. Mater. Environ. Sci. 5 (2), $2014,484-489$

5- H. El Hajjouji., G. Ait Baddi, A. Yaacoubi, H. Hamdi, , P. Winterton, , J.C. Revel, M. Hafidi, , Bioresource Technology. 99, 2008, 5505.

6- J. Rodier, L'analyse de l'eau : Eaux naturelles, eaux résiduaires, eaux de mer, Dunod, ISBN : 978-2-10-054179-9, 2009, pp 976.

7- AFNOR. Recueil de normes françaises : eau, méthodes d'essai, 2e Édition, Paris, France, 1983, pp 621.

8- APHA, American Public Health Association 1992. Standard Methods for Analysis of Waste and Waste Water, APHA. Pub. 18th ed. Washington, Dc.

9- A. Esmail, H, Abed, M. Firdaous, N. Chahboun, Z. Mennane, E. Berny, M. Ouhssine, J. Mater. Environ. Sci.5, 2013, 121-126
10- A. Yangui, M. Abderraba, Food chemistry, 2018, 102-109.

11- J. Murphy, J.P. Riley, A modified single solution method for the determination of phosphate in natural water. Annal. Chim. Acta., 1962, 127.

12- J. Rodier, L'analyse de l'eau : Eaux naturelles, eaux résiduaires, eaux de mer, Dunod, ISBN : 978-2-10-054179-9, 2009, pp 120-121.

13- J. Rodier, L'analyse de l'eau : Eaux naturelles, eaux résiduaires, eaux de mer, Dunod, ISBN : 978-2-10-054179-9, 2009, pp 257.

14- M. Achak, N. Ouazzani, A. Yaacoubi, L. Mandi, Journal of Water Science, vol. 21, $\mathrm{n}^{\circ} 1, \mathbf{2 0 0 8}$, p. 53-67.

15- H. Chimi, Technologies d'extraction de l'huile d'olive et gestion de sa qualité, Bulletin mensuel d'information et de liaison de PNTTA : Maroc, 2006, $\mathrm{N}^{\circ}$ 141, pp.1-4.

16- R. Qadeer, A. H. Rehan, A Study of the Adsorption of Phenol, Turk J Chem 26, 2002, 357361.

17- N. Slimani Alaoui, A. El Laghdach, E. Manuel Cuerda Correa, M. Stitou, F. El Yousfi, N. Jbari, J. Mater. Environ. Sci. 5, 2014, 476-483.

18- A. Aarfane, A. Salhi , M. El Krati , S. Tahiri, M. Monkade , E.K. Lhadi ,M. Bensitel, J. Mater. Environ. Sci. 5, 2014, 1927-1939

19- A. Dabrowski, P. Podkoscielny , Z. Hubicki, M. Barczak, Adsorption of phenolic compound by activated carbon-a critical review. Chemosphere, 2005, 58, 1049-1070

20- K. Belgin, T. Fatma, D. Hakan, J. İlknur, Int. Environmental Application \& Science, 2008, Vol. 3 (5): 373-380.

21- C. Datta, A. Dutta, D. Dutta, S. Chaudhuri, Procedia Food Science 1, Elsevier, 2011, 893-899. 